\title{
Screening of protein kinase inhibitors identifies PKC inhibitors as inhibitors of osteoclastic acid secretion and bone resorption
}

\author{
Mette G Sørensen ${ }^{1}$, Morten A Karsdal ${ }^{1}$, Morten H Dziegiel ${ }^{2}$, Jean A Boutin ${ }^{3}$, Olivier Nosjean ${ }^{3}$, Kim Henriksen ${ }^{1 *}$
}

\begin{abstract}
Background: Bone resorption is initiated by osteoclastic acidification of the resorption lacunae. This process is mediated by secretion of protons through the V-ATPase and chloride through the chloride antiporter CIC-7. To shed light on the intracellular signalling controlling extracellular acidification, we screened a protein kinase inhibitor library in human osteoclasts.

Methods: Human osteoclasts were generated from CD14+ monocytes. The effect of different kinase inhibitors on lysosomal acidification in human osteoclasts was investigated using acridine orange for different incubation times (45 minutes, 4 and 24 hours). The inhibitors were tested in an acid influx assay using microsomes isolated from human osteoclasts. Bone resorption by human osteoclasts on bone slices was measured by calcium release. Cell viability was measured using AlamarBlue.

Results: Of the 51 compounds investigated only few inhibitors were positive in both acidification and resorption assays. Rottlerin, GF109203X, Hypericin and Ro31-8220 inhibited acid influx in microsomes and bone resorption, while Sphingosine and Palmitoyl-DL-carnitine-Cl showed low levels of inhibition. Rottlerin inhibited lysosomal acidification in human osteoclasts potently.

Conclusions: In conclusion, a group of inhibitors all indicated to inhibit PKC reduced acidification in human osteoclasts, and thereby bone resorption, indicating that acid secretion by osteoclasts may be specifically regulated by PKC in osteoclasts.
\end{abstract}

\section{Background}

Bone is continuously remodeled throughout life to react to stress on the skeleton and to repair microfractures [1-3]. Bone is resorbed by the osteoclasts and new bone is formed by the osteoblasts [4]. Bone resorption is mediated through acidification of the resorption lacunae by the osteoclasts. The mineralized bone matrix is dissolved by secretion of protons through a V-ATPase [5-8], which is followed by chloride transport through ClC-7 to maintain electroneutrality [9-13]. At the low $\mathrm{pH}$ in the resorption lacuna cathepsin $\mathrm{K}$ degrades the organic phase of the bone [14,15]. The importance of the acidification process in osteoclasts is illustrated by mutations in the a3 subunit of the V-ATPase and in

\footnotetext{
* Correspondence: kh@nordicbioscience.com

${ }^{1}$ Nordic Bioscience A/S, Herlev Hovedgade 207, DK-2730 Herlev, Denmark Full list of author information is available at the end of the article
}

ClC-7, which lead to osteopetrosis [12,13,16-18]. Furthermore, inhibitors of acid secretion by the osteoclasts have been shown to have promising effects, and are being investigated as potential drug candidates for osteoporosis at the moment $[19,20]$.

The intracellular mechanism underlying acid secretion appears to involve Protein Kinase A (PKA) and Protein Kinase $\mathrm{C}(\mathrm{PKC})$ [21,22], as a study implicated PKA as a negative regulator of acid secretion in rat osteoclasts [23], and another study showed effects with different tyrosine kinase inhibitors in avian osteoclasts [24]. PKC has also been implicated in the acid secretion process in avian osteoclasts, an effect related to reduction of VATPase activity [25]. In avian osteoclasts the tyrosine kinase c-src regulates osteoclastic acid secretion through the chloride channel CLIC5b [26], however, these findings appear to be specific for the avian osteoclasts as they were not reproduced in a human osteoclast based

\section{C) Biomed Central}


system [27], where $\mathrm{ClC}-7$ appears to be the chloride channel of importance $[10,28]$. In summary there is no consensus on the intracellular control of acid secretion in human osteoclasts.

We investigated whether protein kinases play roles in mature human osteoclasts, and whether the roles are related to acid secretion using inhibitors of these kinases and their specific isoform. We used a panel of protein kinase inhibitors in acridine orange based acid secretion assays in whole cells and membrane fractions, as well as human osteoclasts seeded on cortical bone slices to evaluate the effect of the inhibitors on bone resorption.

\section{Methods}

\section{Chemicals}

Chemicals were obtained from SIGMA-ALDRICH A/S and culture media from LIFE TECHNOLOGIES A/S unless specified. Bafilomycin was obtained from Tocris, while the different kinase inhibitors were obtained from BIOMOL International LP.

\section{Cell culture}

The CD14+ isolation was performed as previously described [29]. Briefly, the monocytes were isolated from peripheral blood by centrifugation on a FicollPaque gradient (Amersham Pharmacia), and magnetically sorted using a CD14+ magnetic bead isolation kit (Dynal Biotech). The cells were then seeded in $75 \mathrm{~cm}^{2}$ flasks, and cultured in $\alpha$ MEM containing $10 \%$ fetal calf serum, 100 units $/ \mathrm{mL}$ penicillin, $100 \mu \mathrm{g} / \mathrm{mL}$ streptomycin and $25 \mathrm{ng} / \mathrm{ml}$ of M-CSF for three days, then they were lifted using trypsin and a cell scraper, and cultured until day 10 in the presence of $25 \mathrm{ng} / \mathrm{ml} \mathrm{M-CSF}$ and $25 \mathrm{ng} /$ ml RANKL (R\&D Systems) unless otherwise stated.

The blood was received from the blood bank at the University Hospital of Copenhagen from volunteer donors, which all sign informed consent that the blood can be used for research purposes. The approval is held by the University Hospital of Copenhagen.

\section{Osteoclast resorption}

Mature human osteoclasts were lifted from culture flasks and subsequently seeded on cortical bovine bone slices at a density of 20,000 cells $/ \mathrm{cm}^{2}$ and then culture for 5 days, with refreshment of medium once. The supernatant was collected and the release of calcium was measured. Inhibitors of resorption were added in the medium at different concentrations and compared to vehicle treated osteoclasts (DMSO).

\section{Cortical bovine bone slices}

The bone slices were cut from sticks (Nordic Bioscience A/S), which were made of the cortical bone from cows.
The sticks were cut into small slices with a thickness of $0.2 \mathrm{~mm}$ with a diameter that fits into 96 well plates.

\section{Measurement of calcium}

The concentration of total calcium was measured in the culture supernatants after resorption using a colorimetric assay and a Hitachi 912 Automatic Analyzer (Roche Diagnostics).

\section{Osteoclast acidification assay}

Acridine orange (3,6-bis[Dimethylamine]acridine) at 10 $\mu \mathrm{g} / \mathrm{ml}$ was loaded for $45 \mathrm{~min}$ in the culture medium in the presence or absence of various inhibitors as described previously [27]. The dye was washed away and pictures were taken using an Olympus IX-70 microscope and an Olympus U-MWB filter (x20 objective), or fluorescence was measured using the SpectraMax M5 (Molecular Devices) at excitation $492 \mathrm{~nm}$ and emission $535 \mathrm{~nm}$. The results are presented as percentage of the signal obtained with the positive control Bafilomycin treated condition.

\section{AlamarBlue assay}

To assess cell viability AlamarBlue measurements were performed according to the manufacturer's protocol (Trek Diagnostics Systems Inc.). Briefly, AlamarBlue was diluted 1 to 10 in the cell culture medium, and the color change was monitored carefully. When a switch from blue to purple was observed, the color changes were measured using a plate reader (excitation wavelength $540 \mathrm{~nm}$, emission $590 \mathrm{~nm}$ ). Medium without cells was used as background. The cell viability was measured in mature human osteoclasts seeded on bone slices after the 5-day culture period at termination.

\section{Osteoclast microsomes}

The osteoclast-derived membrane vesicles were isolated using a modification of a protocol published by [28] Briefly, the mature cells were washed two times in PBS, and the cells were lifted by scraping in $10 \mathrm{mM}$ Tris$\mathrm{HCl}, 4 \mathrm{mM}$ EDTA pH7.4 containing Complete Mini EDTA-free protease inhibitor tablet. The collected cells were then homogenized using an Ultraturrax blender and a Teflon homogenizer, and then the homogenized cells were centrifuged at $700 \mathrm{~g}$ to eliminate iron beads and cell remnants. The homogenates were then ultracentrifuged at 40,000 g for 30 minutes, and finally the pellet was resuspended and stored at $-80^{\circ} \mathrm{C}$ until further use.

\section{Influx assay}

The influx assay was performed as previously described $[27,28]$. Briefly, osteoclast membranes were incubated in 
reaction buffer [27]. The reaction was incubated at room temperature for 30 minutes to obtain a steady state. Then the reaction was initiated by addition of ATP at a concentration of $5 \mathrm{mM}$, and immediately after the plate was read in a plate reader using excitation $492 \mathrm{~nm}$ and emission $535 \mathrm{~nm}$. The fluorescence was read every 15 seconds for three minutes. The results are presented as the slope of the influx curves in percent of the vehicle, which represents the rate of the acidification $(\Delta \mathrm{F} / \Delta \mathrm{t})$.

\section{Immunoblotting}

Total cell lysates were prepared by lysing the osteoclasts in RIPA+++ buffer for 5 min [12]. The lysates were centrifuged at 15,000 g for $30 \mathrm{~min}$ to remove any cell debris left. Osteoclast membranes were prepared as described in the paragraph "osteoclast microsomes". Protein concentrations were measured using the Bio-Rad DC protein measurement assay. Ten micrograms of total protein for either the lysate or the membranes were loaded onto a SDS-PAGE gel in sample buffer containing $10 \mathrm{mM}$ dithiotreitol, and electroblotted onto nitrocellulose membranes. The quality of the protein loading was checked by Ponceau Red staining. The membranes were then blocked in TBS-T $(50 \mathrm{mM}$ Tris-base $\mathrm{pH} 7.5$, $100 \mathrm{mM} \mathrm{NaCl}, 0.1 \%$ Tween-20) containing $5 \%$ skim milk powder for $1 \mathrm{~h}$ at ambient temperature. This was followed by overnight incubation at $4{ }^{\circ} \mathrm{C}$ with the correct dilution of the primary antibodies against PKC (A-3) (Santa Cruz) and V-ATPase B2 (Santa Cruz). This was followed by incubation with the corresponding horseradish peroxidase-conjugated secondary antibody for $1 \mathrm{~h}$ at ambient temperature. Finally, the results were visualized using the ECLTM kit (Amersham Pharmacia Biotech).

\section{Statistical analysis}

Statistical analyses were performed using one-way analysis of variance followed by Dunnett's multiple comparison tests. Bartlett's test was used to assess variance homogeneity. Statistical significance is indicated by the number of asterisks, $\mathrm{p}<0.05^{*}, \mathrm{P}<0.01^{* * *}$ and $\mathrm{p}<$ $0.001^{* * * *}$.

\section{Results}

\section{Protein kinase inhibitors in osteoclasts}

51 protein kinase inhibitors were tested at $10 \mu \mathrm{M}$ and at $50 \mu \mathrm{M}$ (data not shown, since $50 \mu \mathrm{M}$ led to more toxicity, without any more specific effects) in a panel of osteoclastic acidification and resorption assays revealing that several inhibitors were positive in bone resorption, i.e. the c-src tyrosine kinase inhibitors PP1 and PP2 as expected (Table $1 \&[30]$ ). In addition, we found that the tyrosine kinase inhibitor Tyrphostin 47 inhibited acid influx, as previously published, on the other hand
Genistein, another tyrosine kinase inhibitor, did not show any inhibitory effects in the tested assays [24]. The mTOR inhibitor Rapamycin showed a minor inhibition of acid influx and bone resorption, without affecting survival, although this was expected from earlier studies $[31,32]$. All in all few compounds were positive in all assays, and in these cases other inhibitors of the same target failed to reproduce the data indicating that the effects were due to non-specific effects (data not shown). However, inhibitors, which are speculated to inhibit PKC showed consistent inhibition of both acid secretion and bone resorption, and thus were analysed in detail. All the results are summarised in Table 1.

\section{The effect of potential PKC inhibitors on lysosomal acidification in mature human osteoclasts}

The acridine orange assay is based on a dye that fluoresces bright orange at lysosomal $\mathrm{pH}$, and becomes green at neutral $\mathrm{pH}$. It has previously been shown to be useful in relation to quantification of lysosomal $\mathrm{pH}$ changes in whole cells, as well as microsomal membranes $[27,33]$, and therefore we used it to assess the effects of various potential PKC inhibitors in detail. GF109203X, Hypericin, Ro31-8220, Sphingosine, HBDDE and PalmitoylDL-carnitine- $\mathrm{Cl}$ were analyzed, and of these inhibitors, only GF109203X showed inhibition of lysosomal acidification and only at the 45 minute time point (Figure $1 \mathrm{~A})$, whereas the others were ineffective. These data were confirmed using quantitative analysis (Figure 1B). All inhibitors were tested after 45 minutes, 4 and 24 hours. However, only the 45 minutes results are shown in figure 1. In addition, Rottlerin was characterized in detail. Rottlerin inhibited lysosomal acidification already after 45 minutes incubation both in the qualitative and the quantitative assay. Due to the potent inhibition observed using Rottlerin further concentrations were tested, and as seen in figure 2, these data clearly show that Rottlerin dose-dependently inhibits lysosomal acidification at 45 minutes (Figure 2), 4 and 24 hours (data not shown). In the acidification experiments Bafilomycin A1 was used as a positive control in accordance to previously published studies $[27,33]$.

\section{The effect of potential PKC inhibitors on acid influx in human osteoclast microsomes}

To further characterize the effects of the inhibitors, we used a membrane-based acid influx assay based on microsomes previously shown to be enriched in $\mathrm{ClC}-7$ indicating a high content of lysosomes, which are the desired sub-cellular fraction $[27,28]$. This assay is based on microsomes from human osteoclasts and it is highly sensitive to the V-ATPase inhibitor Bafilomycin A1, which was used as a positive control (Figure $3 \mathrm{H}$ ) $[27,28]$. 
Table 1 Summary of data for all inhibitors

\begin{tabular}{|c|c|c|c|c|c|c|c|c|}
\hline Target & Inhibitor & $\begin{array}{l}\text { IC50 } \\
(\mu \mathrm{M})\end{array}$ & $\begin{array}{c}\text { Acridine } \\
\text { orange } 45 \\
\text { min. }\end{array}$ & $\begin{array}{l}\text { Acridine orange } \\
\text { Quenching }\end{array}$ & $\begin{array}{l}\text { Influx }-\% \text { Inh. } \\
\text { at } 10 \mu \mathrm{M}\end{array}$ & $\begin{array}{c}\text { Influx } \\
\text { Quenching }\end{array}$ & $\begin{array}{l}\text { Resorption - \% } \\
\text { Inh at } 10 \mu \mathrm{M}\end{array}$ & $\begin{array}{c}\text { Alamar - \% } \\
\text { Inh. at } 10 \mu \mathrm{M}\end{array}$ \\
\hline \multirow[t]{2}{*}{ PDGFRK } & AG-370 & 20 & No & No & 20 & Yes & 0 & 0 \\
\hline & AG-1296 & 1 & No & No & 15 & Yes & 0 & 0 \\
\hline \multirow[t]{2}{*}{ EGFRK/PDGFRK } & AG-494 & 1.2 & No & No & 55 & No & 0 & 0 \\
\hline & Tyrphostin 46 & 9.2 & No & No & 0 & No & 0 & 0 \\
\hline \multirow[t]{9}{*}{ EGFRK } & Lavendustin A & 0.011 & No & No & 0 & No & 0 & 0 \\
\hline & RG-14620 & 3 & No & No & 0 & No & 0 & 0 \\
\hline & Tyrphostin 23 & 35 & No & No & 45 & Yes & 0 & 0 \\
\hline & Tyrphostin 25 & 3 & No & No & 34 & Yes & 0 & 0 \\
\hline & Tyrphostin 47 & 2.4 & No & No & 85 & No & 0 & 0 \\
\hline & Tyrphostin 51 & 0.8 & No & No & 0 & No & 0 & 0 \\
\hline & $\begin{array}{l}\text { Tyrphostin } \\
\text { AG1478 }\end{array}$ & 0.003 & No & No & 0 & No & 43 & 0 \\
\hline & Erbstatin (a) & 0.77 & No & No & 0 & No & 0 & 0 \\
\hline & Erlotinib & 1 & No & No & 0 & No & 100 & 100 \\
\hline NGFRK & AG-879 & 10 & No & No & 100 & No & 22 & 0 \\
\hline EGFRK/CaMKII & Lavendustin C & 2 & No & No & 0 & No & 0 & 0 \\
\hline \multirow[t]{2}{*}{ CaMKII } & $\mathrm{KN}-62$ & 0.9 & No & No & 0 & No & 63 & 0 \\
\hline & $\mathrm{KN}-93$ & 0.37 & No & No & 40 & No & 0 & \\
\hline \multirow[t]{2}{*}{ MEK1/2 } & PD-98059 & 2 & No & No & 0 & No & 0 & 0 \\
\hline & U-0126 & 0.072 & No & No & 0 & No & 0 & 0 \\
\hline p38MAPK & SB203580 & 0.07 & No & No & 0 & No & 0 & 0 \\
\hline \multirow{2}{*}{$\begin{array}{l}\text { PKA, PKG, MLCK, } \\
\text { PKC }\end{array}$} & $\mathrm{H}-7$ & 3.0 & No & No & 0 & No & 0 & 0 \\
\hline & $\mathrm{H}-9$ & 1.9 & No & No & 0 & No & 0 & 0 \\
\hline \multirow[t]{5}{*}{$P K C$} & GF-109203X & 0.02 & Yes & No & 100 & No & 100 & 0 \\
\hline & Hypericin & 3.4 & No & No & 82 & Yes & 100 & 95 \\
\hline & Ro 31-8220 & 0.01 & No & No & 79 & Yes & 100 & 100 \\
\hline & Sphingosine & $1-3$ & No & No & $15^{*}$ & No & 0 & 0 \\
\hline & $\begin{array}{l}\text { Palmitoyl-DL- } \\
\text { Carnitine-Cl }\end{array}$ & 25 & No & No & $17^{*}$ & No & 0 & 0 \\
\hline$P K C \delta$ & Rottlerin & $3-6$ & Yes & No & 100 & No & 100 & 90 \\
\hline$P K C \alpha / \gamma$ & HBDDE & 43 & No & No & 58 & Yes & 0 & 0 \\
\hline PKA & $\mathrm{H}-89$ & 0.048 & No & No & 0 & No & 0 & 0 \\
\hline \multirow[t]{3}{*}{ PKA/PKG } & $\mathrm{H}-8$ & 0.48 & No & No & 0 & No & 0 & 0 \\
\hline & HA-1004 & 30 & No & No & 0 & No & 0 & 0 \\
\hline & HA-1077 & 1.6 & No & No & 0 & No & 0 & 0 \\
\hline HER1-2 & AG-825 & 0.35 & No & No & 43 & Yes & 0 & 0 \\
\hline Tyrosine & $\begin{array}{l}\text { Tyrphostin } \\
\text { AG1288 }\end{array}$ & 21 & No & No & 88 & No & 0 & 0 \\
\hline \multirow[t]{2}{*}{ Kinases } & $\begin{array}{l}\text { Tyrphostin } \\
\text { AG1295 }\end{array}$ & 25 & No & No & 0 & No & 0 & 0 \\
\hline & Genistein & 0.002 & No & No & 0 & No & 0 & 0 \\
\hline IRK & HNMPA & 10 & No & No & 0 & No & 0 & 0 \\
\hline JNK & SP 600125 & 0.04 & No & No & 0 & No & 0 & 0 \\
\hline p56 Ick & Damnacanthal & 0.017 & No & No & 0 & No & 47 & 0 \\
\hline Syk & Piceatannol & 10 & No & No & 0 & No & 0 & 0 \\
\hline \multirow[t]{2}{*}{ Src family } & PP1 & 0.005 & No & No & 0 & No & 78 & 0 \\
\hline & PP2 & 0.004 & No & No & 0 & No & 100 & 45 \\
\hline JAK-2 & AG-490 & $\sim 5$ & No & No & 0 & No & 0 & 0 \\
\hline
\end{tabular}


Table 1 Summary of data for all inhibitors (Continued)

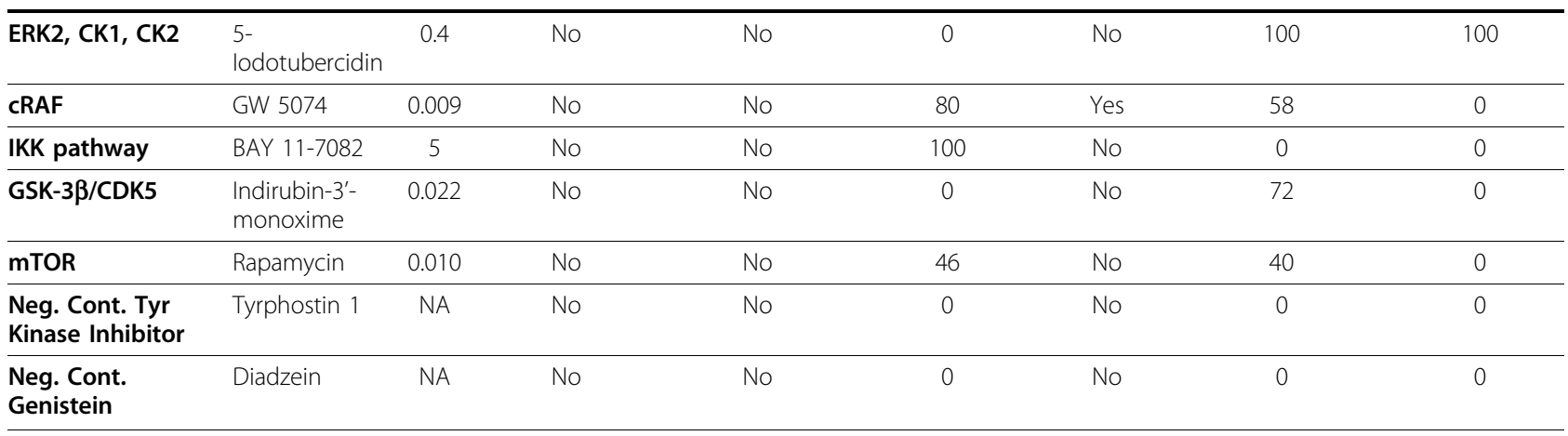

The table summarizes data for the acidification assay using acridine orange ( 45 minute incubation) and the \%-inhibition in the acid influx assay at $10 \mu \mathrm{M}$. It is stated whether the compounds quench the acridine orange signal. The \%-inhibition in the bone resorption and AlamarBlue assay are also provided for each inhibitor tested. *Indicates auto fluorescence of the compound. Text in italics shows the compounds shown in the figures. \# indicates lowest IC50 values obtained in relevant assays http://www.enzolifesciences.com. NA indicates not applicable (for negative controls).

GF109203X (Figure 3A), Hypericin (Figure 3B), and Ro31-8220 (Figure 3C) inhibited acid influx albeit with different potencies, whereas the compounds Sphingosine (Figure 3D) and Palmitoyl-DL-carnitine Cl (Figure 3E) showed only low levels of inhibition, likely due to low potency, or alternatively due to phase partitioning into the lipid bilayer since these molecules are lipid-like. Of these general PKC inhibitors, GF109203X inhibited acid influx potently. In addition, Rottlerin inhibited the acid influx potently and to the same level as GF109203X (Figure 3G), while HBDDE showed some inhibition of acid influx (Figure 3F).
The effect of potential PKC inhibitors on bone resorption by human osteoclasts

To investigate whether the effects of the inhibitors in the acidification assays were paralleled by inhibition of bone resorption by human osteoclasts, the different compounds were tested in a dose-response, again using Bafilomycin A1 as a positive control (figure 4H) [27,28].

All the inhibitors, except HBDDE, reduced bone resorption (Figure 4 and table 1 ), and their potencies in the resorption assay correlated well with the potencies observed in the acidification-based assays, with GF109203X being the most potent and Palmitoyl-DL-

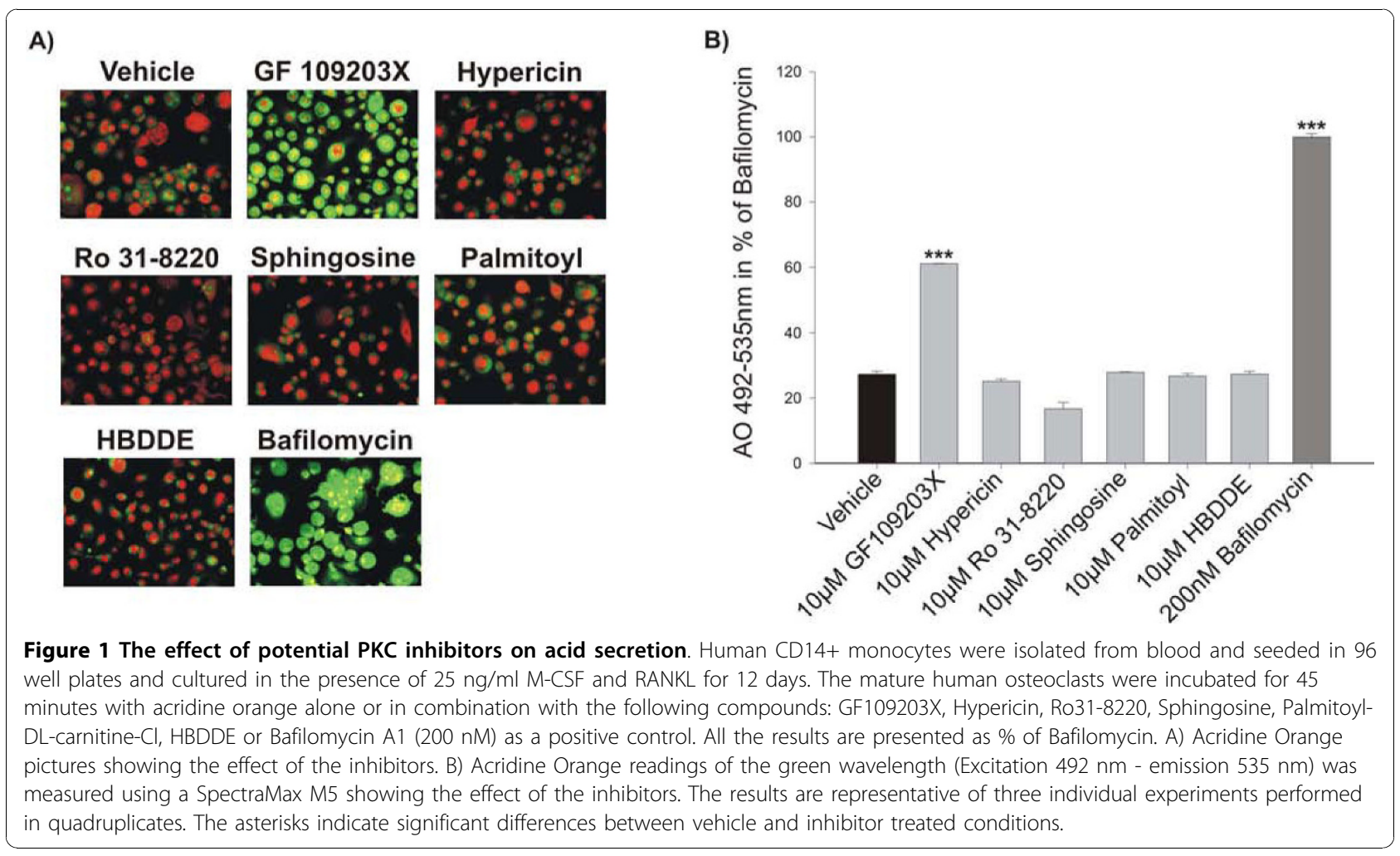




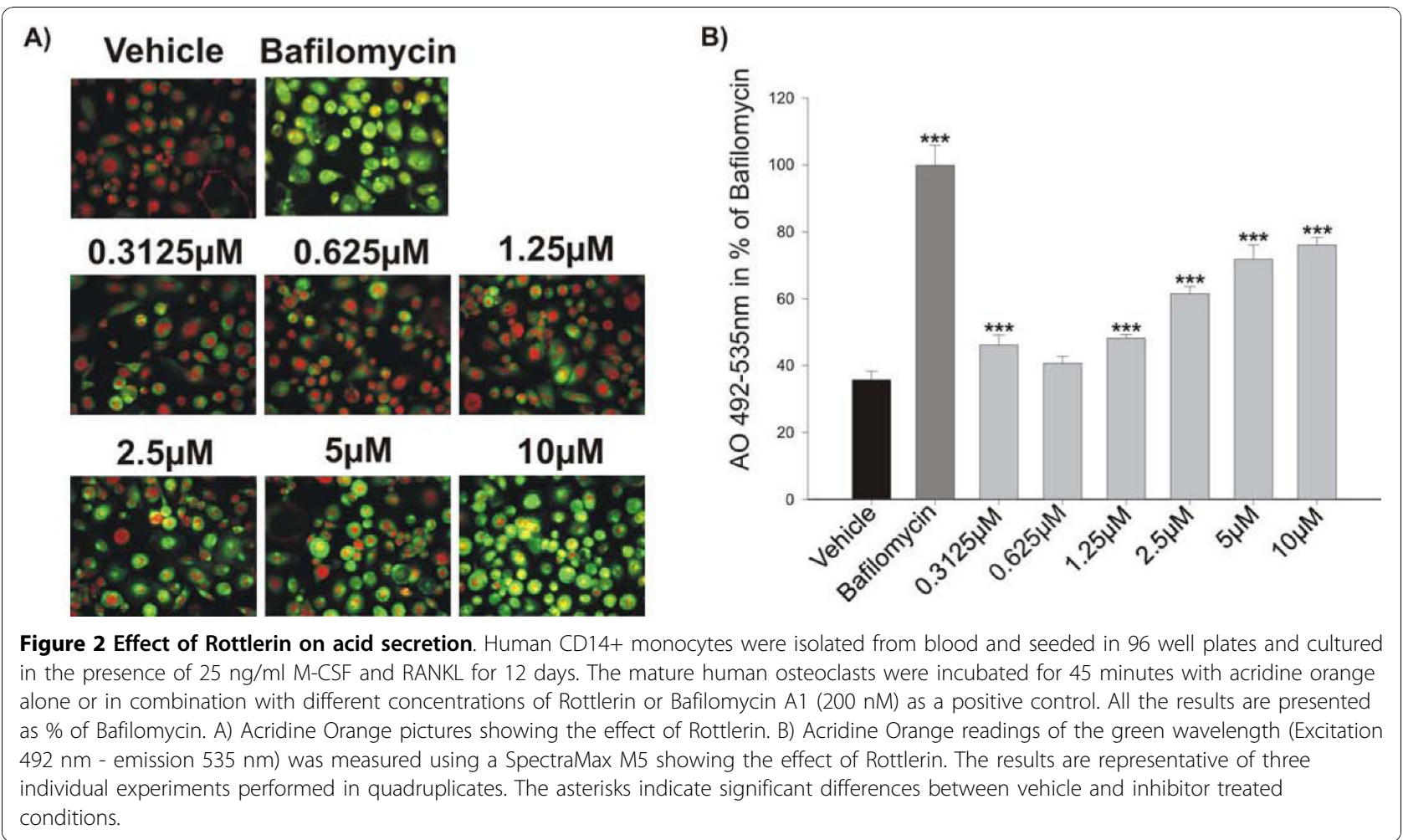

Carnitine $\mathrm{Cl}$ the least potent. Some toxicity of the compounds was observed. Only GF109203X was not toxic at the tested concentrations up to $10 \mu \mathrm{M}$ (figure $4 \mathrm{~A}$ ), while Hypericin (figure 4B) showed toxicity at $10 \mu \mathrm{M}$ but not at $1 \mu \mathrm{M}$ and therefore a separation between inhibition of resorption and reduction of cell viability was seen. Palmitoyl-DL-Carnitine D1 (figure 4E) inhibited bone resorption at a high concentration, and at 90 $\mu \mathrm{M}$ the compound showed toxicity, thus making it difficult to distinguish real anti-resorptive effects from toxicity. In addition, Ro31-8220 and Sphingosine exhibited toxic effects (Figure 4C and 4D).

Rottlerin potently inhibited bone resorption (Figure 4G), whereas HBDDE had no effect (Figure 4F). Furthermore, Rottlerin reduced cell viability; however, as seen for the other inhibitors there was a clear distinction between the effect on bone resorption and the effect on cell viability.

\section{Detection of PKC by Western blotting}

To ensure that PKC was present in the microsomes, isolated from the human osteoclasts, used to analyze acid influx, Western blotting was performed. As a reference a whole cell lysate from human osteoclasts was also analyzed. PKC ( $80 \mathrm{kDa})$ was found in both the osteoclast membranes and in the osteoclast lysate (Figure 5). In addition, V-ATPase B2 was used as a positive control and was shown to be expressed in both osteoclast lysate and osteoclast membranes as expected [28,34].

\section{Discussion}

Previous studies have indicated that various types of protein kinases are involved in acid production by osteoclasts from various species; however, whether this is true for pure human osteoclasts was not clear. We have used a panel of inhibitors targeting a broad range of protein kinases in a recently published series of assays [27] to investigate how acid secretion and bone resorption by mature human osteoclasts are controlled.

We found that very few of the inhibitors inhibited more than one process, if any at all, in the osteoclasts (see table 1), although the inhibitors were used at concentrations, which often far exceeded their reported IC50 values. Surprisingly our data showed that the c-src kinase inhibitors PP1 and PP2 had no effect on acidification, although this has previously been published using avian osteoclasts [26]. As expected both c-src inhibitors reduced bone resorption [30]. One possible explanation for this discrepancy is the species difference, as previous studies have indicated that the regulation of acid secretion between human and avian osteoclasts is different also with respect to the chloride channels involved [11,26-28]. Further supporting the difference between human and avian osteoclasts, we did not find any inhibitory effects of Genistein, neither on resorption nor acid secretion, which is in contrast to the findings of Williams et al. [24]. Furthermore, other studies have highlighted that Genistein reduces bone resorption 


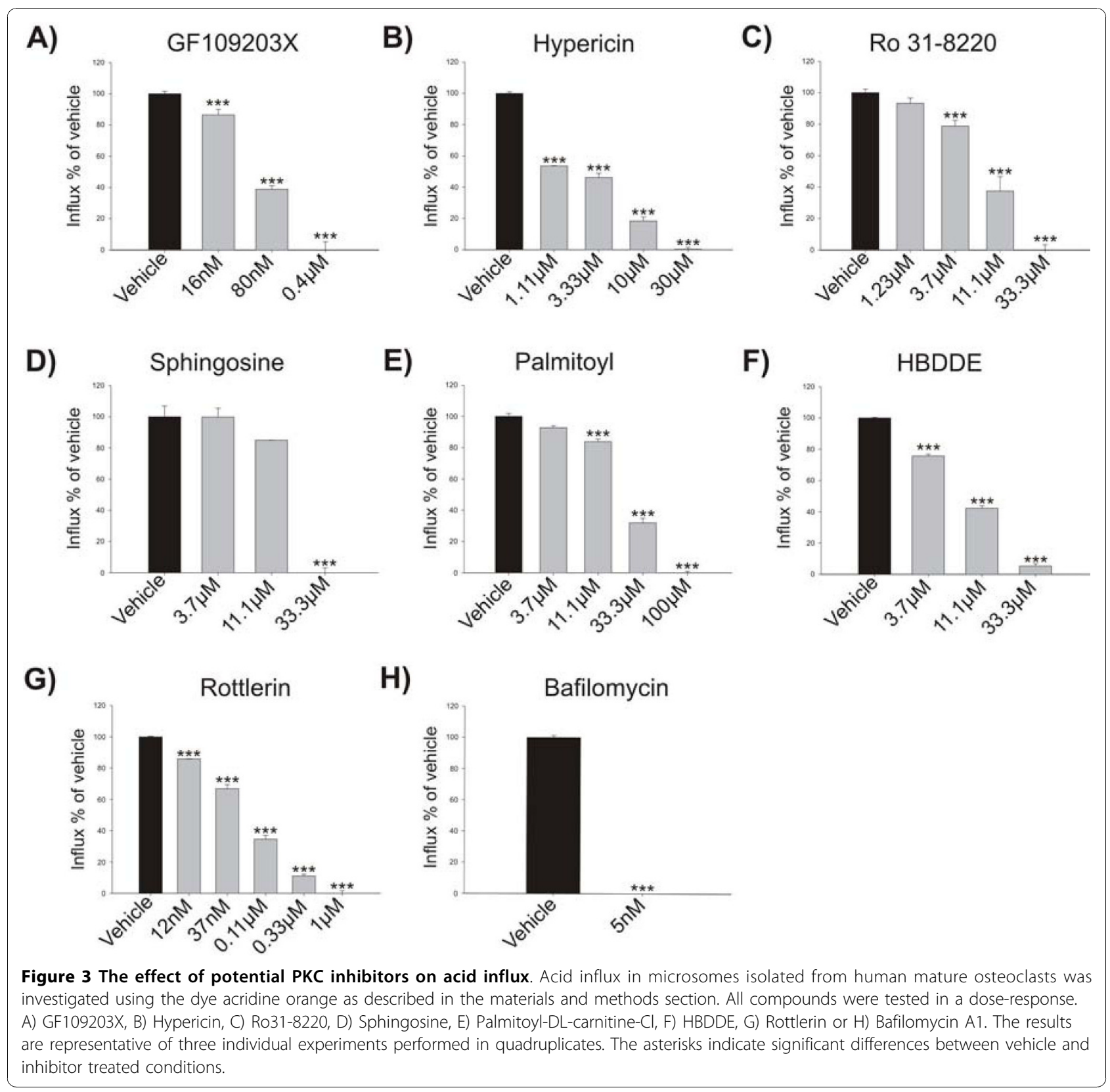

[35-37], but these results were found in differentiating osteoclasts. In addition, Genistein has been indicated to activate PPAR $\gamma$ [38], a receptor involved in osteoclastogenesis, again showing that it attenuates osteoclastogenesis [39]. With respect to effects of Genistein, and the other general tyrosine kinase inhibitors (Tyrphostin AG1288 and Tyrphostin AG1295) on mature osteoclasts, we were surprised that they did not have any effects on bone resorption or osteoclast viability, since these effects were expected due to inhibition of c-src and c-fms [24,40-43]. We speculate that the combination of short time span, the low potency and selectivity of these compounds combined with the high doses of RANKL and M-CSF used in the culture system are the causes for the lack of effect of these compounds.

In osteoclasts of various origin both PKA and PKC have been associated with acid secretion under different circumstances $[23,25]$, and thus their roles in the regulation of acid secretion were of high interest; however, no effects of the PKA inhibitors were detected. This correlates with the findings of Kajiya et al. [23], who found that PKA activators inhibited acid secretion in rat osteoclasts, and that PKA inhibitors protected against calcitonin mediated inhibition of acid secretion. In contrast, it 


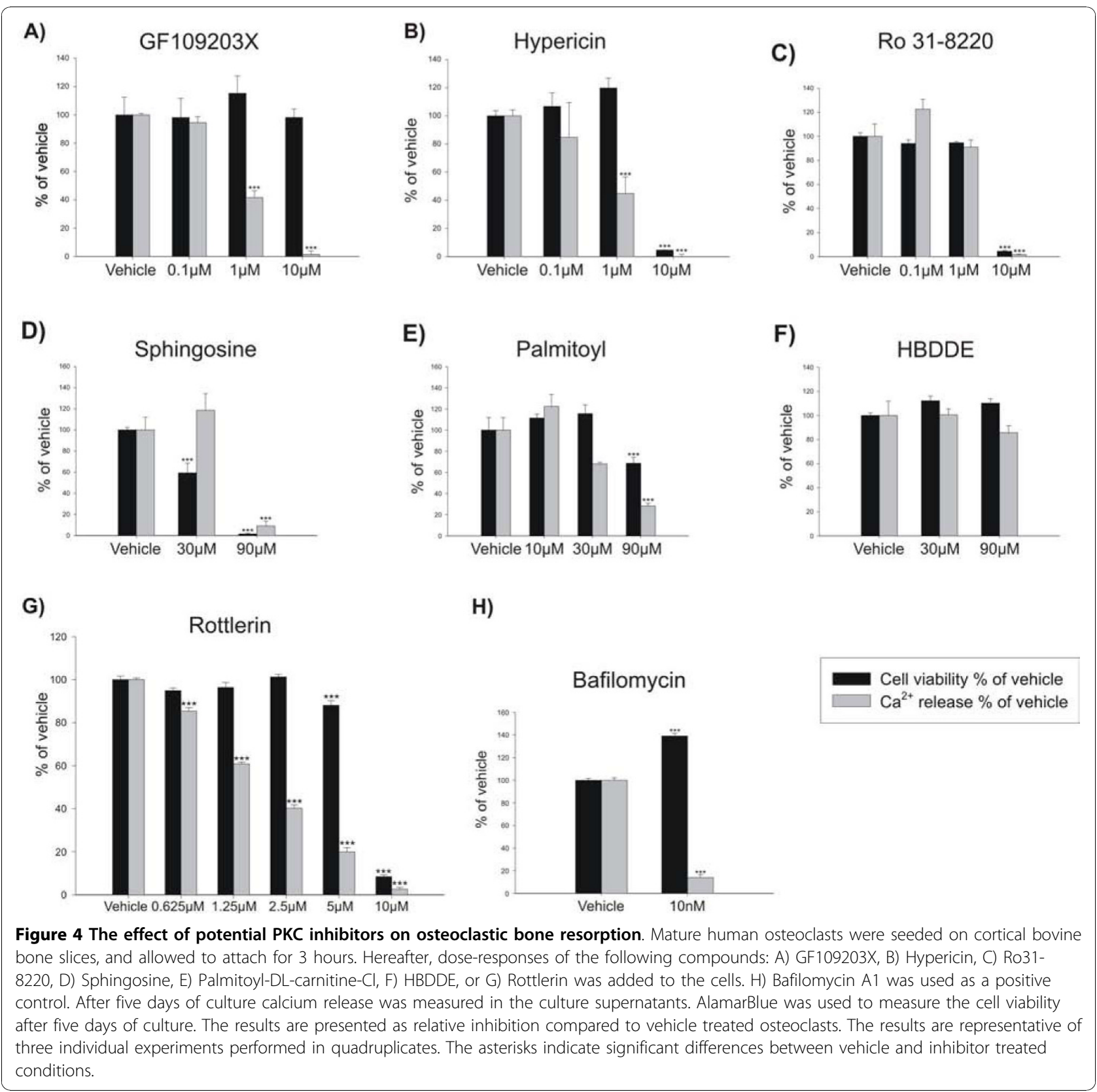

was shown that inhibition of PKA-cAMP signaling reduced bone resorption by mouse osteoclasts [44], however, we could not reproduce these findings using PKA inhibitors in the human system, indicating that different species of osteoclasts utilize different signaling cascades to control bone resorption.

The most potent inhibitors of acid influx and bone resorption were all compounds indicated to inhibit PKC. The most potent inhibitor of acid influx and bone resorption was GF109203X, which is known to be somewhat selective for PKC [45]. In the cell-based acidification assay GF109203X inhibited only at 45 minutes, but not at the other time points, due to a yet unidentified reason. Interestingly Rottlerin, a molecule indicated to inhibit the PKC $\delta$ isoform was equally potent as GF109203X but in addition it also inhibits the acidification in intact human osteoclasts. These data indicate that PKC and maybe more specific PKC $\delta$ plays a role in controlling acid secretion, and thus bone resorption by human osteoclasts. These data correlate well with a study implicating PKC as involved in the acid secretion in avian osteoclasts [25]. Furthermore, studies have indicated that PKC is involved in transient shape changes in osteoclasts $[46,47]$; however, whether these changes 


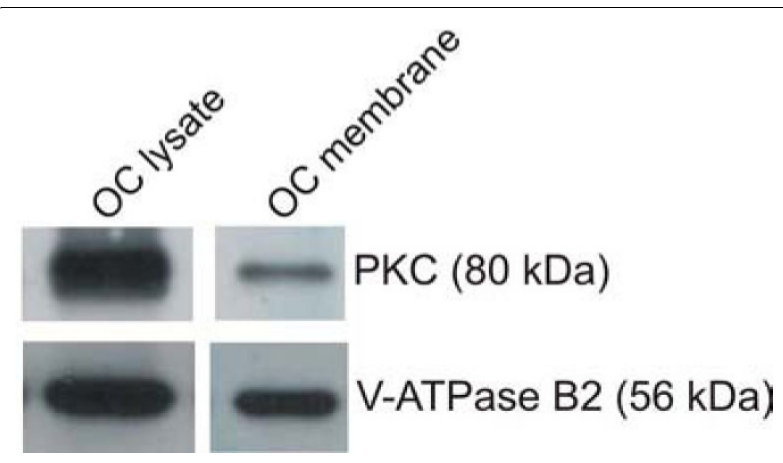

Figure 5 Detection of PKC in both osteoclast membranes and osteoclast lysate. CD14+ monocytes were cultured in the presence of M-CSF and RANKL for 12 days to mature osteoclasts were present. The osteoclasts were either used to make a lysate of mature human osteoclasts using RIPA+++, or they were used for microsome isolation. The expression of PKC, together with V-ATPase B2 as a positive control, was analyzed by loading $10 \mu \mathrm{g}$ of lysates and microsomes on SDS-PAGE gels with subsequent immunoblotting.

have anything to do with lowered acidification remains to be clarified.

Toxicity was observed for Rottlerin in the bone resorption assay, but only at the $10 \mu \mathrm{M}$ concentration. However, the inhibitor effect of Rottlerin on acid influx and bone resorption was apparent at lower doses, indicating that inhibition of acid influx and bone resorption is through PKC inhibition at low concentrations, while the high concentrations non-specific effects lead to toxicity, such as those described in the following section.

However, although Rottlerin has been shown to be a potent inhibitor of PKC $[48$ ], others have shown that Rottlerin has several other effects, and for example it strongly suppresses CHK2, PLK1, PIM3, SRPK1 [49], p38-MAPK, PKA and GSK-3b [50]. Furthermore, it has been shown that Rottlerin decreases RANK expression in macrophages, most likely by a PKC-independent pathway [51]. However, the cells used by Kang et al. [51] were U937 cells, which are used to study differentiation of monocytes to macrophages. An osteoclasts precursor cell cannot be compared to the system with mature human osteoclasts used in this study. In addition, the RANK expression does not affect the acidification, and Rottlerin seems to inhibit acidification in the mature human osteoclasts.

Like Rottlerin, GF109203X has also been shown to have other effects than as a PKC inhibitor. It has for example been shown to inhibit C1q-induced P-selectin expression [52], inhibition of activated ERK [53], and inhibition of NHE1 activity [54].

These findings indicate that both Rottlerin and GF109203X are too weak and non-specific inhibitors to be useful in cell-based studies. Furthermore, other off target effects of Rottlerin on mitochondrial function [55,56], and as a protonophore [57], question whether the effect we observed is indeed through inhibition of PKC $\delta$. A protonophore will collapse all acid transport [58], however, it appears unlikely that collapsing all proton gradients will not affect osteoclast survival, and thus we speculate that the inhibition of resorption is unrelated to the protonophore effect. Furthermore, other inhibitors indicated to inhibit PKC also reduced acid secretion and bone resorption, potentially indicating a role of PKC in osteoclast-mediated acidification, although the specificity of all inhibitors should be interpreted with skepticism $[50,59]$.

With respect to the commercially reported in vitro IC50 values, our data do not always correlate well with these, as underlined by the fact that both rottlerin and GF109203X both are very potent in our assays, and yet their in vitro IC50 values are far apart (see table 1). Furthermore, as illustrated throughout the manuscript IC50 values are highly assay dependent, and thus comparison of IC50 values between assays is difficult and should be done considering all the factors in play, such as membrane-permeability, access to the ruffled border, and the assay itself.

Furthermore, the discrepancies between acid influx and acidification in intact osteoclasts are not fully clear yet. Some of the inhibitors are effective inhibitors of bone resorption and acid influx, but they do not inhibit the acidification in whole cells. This can be because of the concentration and time-line used for the acidification study in whole cells. The bone resorption assay is a 5-day assay and could lead to more false positives due to this, compared to the acidification assay in which up to 24 hours incubation were tested. Henriksen et al. [27] have previously shown that the high concentrations needed to observe inhibition in the cell-based acridine orange assay can lead to unclear results. In addition, the acid influx data often correlates better with the effects on bone resorption. These findings are further illustrated by the discrepancies between the time-line for inhibition of cellbased acridine orange between GF109203X and Rottlerin. However, in acid influx assay problems due to quenching of the acridine orange signal are seen leading to false positive in the assay. Confirming the relevance of studying PKC in membrane fractions, we found that PKC is indeed present in the osteoclast microsomes, and since it is well-known that PKC can be found in two conformations; an inactive and an active form, of which the active is membrane-bound [60-62]. Thus, the system used in the influx assay contains PKC in its active membrane bound conformation.

For the validation of the results found in this study, using siRNA would be of interest, and could in the future provide important data. However, due to 
difficulties in getting robust transfection and knockdown in human osteoclasts, this has not yet been feasible.

\section{Conclusions}

In this study we presented the analysis of a panel of protein kinase inhibitors in acidification of the resorption lacunae and bone resorption by human osteoclasts. However, it should be noted that some of the results are clouded by the difficulties involved in separating toxic effects from relevant inhibitory effects, as well as separating inhibition of fluorescent signals from quenching related effects, especially at the high concentrations used for some of the compounds. Furthermore, the specificity of the inhibitors is often not very high, and this is clearly illustrated by the fact that one of the most potent inhibitor of bone resorption and acid secretion, Rottlerin, has been indicated to exert a function as a protonionophore [63], which thus would explain its highly potent effect in all the assays. However, the compound is not overtly toxic in the long term cultures used for testing bone resorption, which is surprising for a compound eliminating all proton gradients in a whole cell. Furthermore, our finding that both GF109203X and Rottlerin inhibit acid secretion and bone resorption potently, support a role for PKC in the acidification process in human osteoclasts.

\section{Acknowledgements}

This work has received funds from the Danish ministry of "Science, Technology and Innovation". Furthermore, we gratefully acknowledge the funding from the Danish Research Foundation (Den Danske Forskningsfond) supporting this work.

\section{Author details}

${ }^{1}$ Nordic Bioscience A/S, Herlev Hovedgade 207, DK-2730 Herlev, Denmark. ${ }^{2}$ Blodbanken, Copenhagen University Hospital, Blegdamsvej 9, DK-2100 Copenhagen, Denmark. ${ }^{3}$ Institut de Recherche Servier (IdRS), 125 Chemin de Ronde, 78290 Croissy-sur-Seine, France.

\section{Authors' contributions}

MGS designed the experiments, performed the acridine orange analyses, the influx experiments, the bone resorption experiments, and drafted the manuscript. MAK and $\mathrm{KH}$ participated in experiment design and have helped to draft the manuscript. MHD was responsible for collection of the human blood samples. JAB and ON helped to draft the manuscript. All authors have read and approved the final manuscript.

\section{Competing interests}

Morten A. Karsdal is currently employed by and owns stocks in Nordic Bioscience. Mette G. Sørensen and Kim Henriksen are currently employed by Nordic Bioscience but own no stocks in the company. Jean A Boutin and Olivier Nosjean are currently employed by Institut de Recherche Servier (IdRS). All other authors have no conflicts of interest.

Received: 13 November 2009 Accepted: 26 October 2010 Published: 26 October 2010

\section{References}

1. Baron R: General Principles of Bone Biology. In Primer on the Metabolic Bone Diseases and Disorders of Mineral Metabolism 2005, 1-8.
2. Marks SC, Hermey DC: The Structure and Development of Bone. Principles of Bone Biology California, USA.: Academic press 1996, 3-15.

3. Karsdal MA, Martin TJ, Bollerslev J, Christiansen C, Henriksen K: Are nonresorbing osteoclasts sources of bone anabolic activity? J Bone Miner Res 2007, 22:487-494.

4. Seeman E, Delmas PD: Bone quality-the material and structural basis of bone strength and fragility. N Engl J Med 2006, 354:2250-2261.

5. Sundquist K, Lakkakorpi P, Wallmark B, Vaananen K: Inhibition of osteoclast proton transport by bafilomycin $\mathrm{A} 1$ abolishes bone resorption. Biochem Biophys Res Commun 1990, 168:309-313.

6. Taranta A, Migliaccio S, Recchia I, Caniglia M, Luciani M, De Rossi G, et al: Genotype-phenotype relationship in human ATP6i-dependent autosomal recessive osteopetrosis. Am J Pathol 2003, 162:57-68.

7. Baron R, Neff L, Louvard D, Courtoy PJ: Cell-mediated extracellular acidification and bone resorption: evidence for a low $\mathrm{pH}$ in resorbing lacunae and localization of a $100-\mathrm{kD}$ lysosomal membrane protein at the osteoclast ruffled border. J Cell Biol 1985, 101:2210-2222.

8. Li YP, Chen W, Liang Y, Li E, Stashenko P: Atp6i-deficient mice exhibit severe osteopetrosis due to loss of osteoclast-mediated extracellular acidification. Nat Genet 1999, 23:447-451.

9. al Awqati Q: Chloride channels of intracellular organelles. Curr Opin Cell Biol 1995, 7:504-508.

10. Graves $\mathrm{AR}$, Curran $\mathrm{PK}$, Smith $\mathrm{CL}$, Mindell JA: The $\mathrm{Cl}(-) / \mathrm{H}(+)$ antiporter $\mathrm{ClC}-7$ is the primary chloride permeation pathway in lysosomes. Nature 2008.

11. Schlesinger PH, Blair HC, Teitelbaum SL, Edwards JC: Characterization of the osteoclast ruffled border chloride channel and its role in bone resorption. J Biol Chem 1997, 272:18636-18643.

12. Henriksen K, Gram J, Schaller S, Dahl BH, Dziegiel MH, Bollerslev J, et al: Characterization of osteoclasts from patients harboring a G215R mutation in ClC-7 causing autosomal dominant osteopetrosis type II. Am J Pathol 2004, 164:1537-1545.

13. Kornak U, Kasper D, Bosl MR, Kaiser E, Schweizer M, Schulz A, et al: Loss of the CIC-7 chloride channel leads to osteopetrosis in mice and man. Cell 2001, 104:205-215.

14. Gelb BD, Shi GP, Chapman HA, Desnick RJ: Pycnodysostosis, a lysosomal disease caused by cathepsin K deficiency. Science 1996, 273:1236-1238.

15. Saftig P, Hunziker E, Wehmeyer O, Jones S, Boyde A, Rommerskirch W, et al: Impaired osteoclastic bone resorption leads to osteopetrosis in cathepsin-K-deficient mice. Proc Natl Acad Sci USA 1998, 95:13453-13458.

16. Frattini A, Orchard PJ, Sobacchi C, Giliani S, Abinun M, Mattsson JP, et al: Defects in TCIRG1 subunit of the vacuolar proton pump are responsible for a subset of human autosomal recessive osteopetrosis. Nat Genet 2000, 25:343-346.

17. Kornak U, Schulz A, Friedrich W, Uhlhaas S, Kremens B, Voit T, et al: Mutations in the a3 subunit of the vacuolar $\mathrm{H}(+)$-ATPase cause infantile malignant osteopetrosis. Hum Mol Genet 2000, 9:2059-2063.

18. Cleiren E, Benichou O, Van Hul E, Gram J, Bollerslev J, Singer FR, et al: Albers-Schonberg disease (autosomal dominant osteopetrosis, type II) results from mutations in the CICN7 chloride channel gene. Hum Mol Genet 2001, 10:2861-2867.

19. Schaller S, Henriksen K, Sveigaard C, Heegaard AM, Helix N, Stahlhut M, et al: The chloride channel inhibitor n53736 prevents bone resorption in ovariectomized rats without changing bone formation. $J$ Bone Miner Res 2004, 19:1144-1153.

20. Karsdal MA, Henriksen K, Sorensen MG, Gram J, Schaller S, Dziegiel MH, et al: Acidification of the osteoclastic resorption compartment provides insight into the coupling of bone formation to bone resorption. Am J Pathol 2005, 166:467-476.

21. Teti A, Colucci S, Grano M, Argentino L, Zambonin ZA: Protein kinase C affects microfilaments, bone resorption, and [Ca2+]o sensing in cultured osteoclasts. Am J Physiol 1992, 263:C130-C139.

22. Beene DL, Scott JD: A-kinase anchoring proteins take shape. Curr Opin Cell Biol 2007, 19:192-198.

23. Kajiya H, Okamoto F, Fukushima H, Okabe K: Calcitonin inhibits proton extrusion in resorbing rat osteoclasts via protein kinase A. Pflugers Arch 2003, 445:651-658

24. Williams JP, Jordan SE, Barnes S, Blair HC: Tyrosine kinase inhibitor effects on avian osteoclastic acid transport. Am J Clin Nutr 1998, 68:1369S-1374S.

25. Williams JP, Thames AM, McKenna MA, McDonald JM: Differential effects of calmodulin and protein kinase $C$ antagonists on bone resorption and acid transport activity. Calcif Tissue Int 2003, 73:290-296. 
26. Edwards JC, Cohen C, Xu W, Schlesinger PH: c-Src control of chloride channel support for osteoclast $\mathrm{HCl}$ transport and bone resorption. J Biol Chem 2006, 281:28011-28022.

27. Henriksen K, Sorensen MG, Jensen VK, Dziegiel MH, Nosjean O, Karsdal MA: Ion transporters involved in acidification of the resorption lacuna in osteoclasts. Calcif Tissue Int 2008, 83:230-242.

28. Henriksen K, Gram J, Neutzsky-Wulff AV, Jensen VK, Dziegiel MH, Bollerslev J, et al: Characterization of acid flux in osteoclasts from patients harboring a G215R mutation in CIC-7. Biochem Biophys Res Commun 2009, 804-809.

29. Karsdal MA, Hjorth P, Henriksen K, Kirkegaard T, Nielsen KL, Lou H, et al: Transforming growth factor-beta controls human osteoclastogenesis through the p38 MAPK and regulation of RANK expression. J Biol Chem 2003, 278:44975-44987.

30. Furuyama N, Fujisawa Y: Regulation of collagenolytic protease secretion through c-Src in osteoclasts. Biochem Biophys Res Commun 2000, 272:116-124.

31. Glantschnig H, Fisher JE, Wesolowski G, Rodan GA, Reszka AA: M-CSF, TNFalpha and RANK ligand promote osteoclast survival by signaling through mTOR/S6 kinase. Cell Death Differ 2003, 10:1165-1177.

32. Ory B, Moriceau G, Redini F, Heymann D: mTOR inhibitors (rapamycin and its derivatives) and nitrogen containing bisphosphonates: bi-functional compounds for the treatment of bone tumours. Curr Med Chem 2007, 14:1381-1387.

33. Sorensen MG, Henriksen K, Neutzsky-Wulff AV, Dziegiel MH, Karsdal MA: Diphyllin, a Novel and Naturally Potent V-ATPase Inhibitor, Abrogates Acidification of the Osteoclastic Resorption Lacunae and Bone Resorption. J Bone Miner Res 2007, 22:1640-1648.

34. Lee BS, Holliday LS, Ojikutu B, Krits I, Gluck SL: Osteoclasts express the B2 isoform of vacuolar $\mathrm{H}(+)$-ATPase intracellularly and on their plasma membranes. Am J Physiol 1996, 270:C382-C388.

35. Blair HC, Jordan SE, Peterson TG, Barnes S: Variable effects of tyrosine kinase inhibitors on avian osteoclastic activity and reduction of bone loss in ovariectomized rats. J Cell Biochem 1996, 61:629-637.

36. Yamaguchi $M, G a o$ YH: Inhibitory effect of genistein on bone resorption in tissue culture. Biochem Pharmacol 1998, 55:71-76.

37. Li B, Yu S: Genistein prevents bone resorption diseases by inhibiting bone resorption and stimulating bone formation. Biol Pharm Bull 2003, 26:780-786.

38. Dang ZC, Audinot V, Papapoulos SE, Boutin JA, Lowik CW: Peroxisome proliferator-activated receptor gamma (PPARgamma) as a molecular target for the soy phytoestrogen genistein. J Biol Chem 2003, 278:962-967.

39. Wan Y, Chong LW, Evans RM: PPAR-gamma regulates osteoclastogenesis in mice. Nat Med 2007, 13:1496-1503.

40. El HD, Gallet M, Mentaverri R, Sevenet N, Brazier M, Kamel S: Imatinib mesylate (Gleevec) enhances mature osteoclast apoptosis and suppresses osteoclast bone resorbing activity. Eur J Pharmacol 2006, 551:27-33.

41. Ohno H, Kubo K, Murooka H, Kobayashi Y, Nishitoba T, Shibuya M, et al: A c-fms tyrosine kinase inhibitor, Ki20227, suppresses osteoclast differentiation and osteolytic bone destruction in a bone metastasis model. Mol Cancer Ther 2006, 5:2634-2643.

42. Recchia I, Rucci N, Funari A, Migliaccio S, Taranta A, Longo M, et al: Reduction of c-Src activity by substituted 5,7-diphenyl-pyrrolo[2,3-d]pyrimidines induces osteoclast apoptosis in vivo and in vitro. Involvement of ERK1/2 pathway. Bone 2004, 34:65-79.

43. Soriano P, Montgomery C, Geske R, Bradley A: Targeted disruption of the c-src proto-oncogene leads to osteopetrosis in mice. Cell 1991, 64:693-702.

44. Park YG, Kim YH, Kang SK, Kim CH: CAMP-PKA signaling pathway regulates bone resorption mediated by processing of cathepsin $\mathrm{K}$ in cultured mouse osteoclasts. Int Immunopharmacol 2006, 6:947-956.

45. Goekjian PG, Jirousek MR: Protein kinase $C$ in the treatment of disease: signal transduction pathways, inhibitors, and agents in development. Curr Med Chem 1999, 6:877-903.

46. Holloway WR, Collier FM, Herbst RE, Hodge JM, Nicholson GC: Complex shape changes in isolated rat osteoclasts: involvement of protein kinase C in the response to calcitonin. Calcif Tissue Int 1997, 61:306-312.

47. Yamamoto Y, Yamamoto Y, Udagawa N, Okumura S, Mizoguchi T, Take I, et al: Effects of calcitonin on the function of human osteoclast-like cells formed from CD14-positive monocytes. Cell Mol Biol (Noisy -le-grand) 2006, 52:25-31.

48. Gschwendt M, Muller HJ, Kielbassa K, Zang R, Kittstein W, Rincke G, et al: Rottlerin, a novel protein kinase inhibitor. Biochem Biophys Res Commun 1994, 199:93-98.

49. Bain J, Plater L, Elliott M, Shpiro N, Hastie CJ, McLauchlan H, et al: The selectivity of protein kinase inhibitors: a further update. Biochem J 2007, 408:297-315.

50. Davies SP, Reddy H, Caivano M, Cohen P: Specificity and mechanism of action of some commonly used protein kinase inhibitors. Biochem J 2000, 351:95-105.

51. Kang HS, Park EK, Kim KH, Park JY, Choi JY, Shin Hl, et al: Receptor activator of nuclear factor-kappaB is induced by a rottlerin-sensitive and p38 MAP kinase-dependent pathway during monocyte differentiation. Mol Cells 2004, 17:438-445.

52. Skoglund $C$, Wettero J, Tengvall P, Bengtsson T: C1q induces a rapid upregulation of $\mathrm{P}$-selectin and modulates collagen- and collagen-related peptide-triggered activation in human platelets. Immunobiology 2010.

53. Hanieh $H$, Abe $A$, Kondo $Y$ : Extracellular signal-regulated kinase (ERK) activation in chicken heterophils stimulated with phorbol 12-myristate 13-acetate (PMA), formyl-methionylleucyl-phenylalanine (fMLP) and lipopolysaccharide (LPS). Anim Sci J 2009, 80:577-584.

54. Kato K, Yasutake M, Jia D, Snabaitis AK, Avkiran M, Kusama Y, et al: Urotensin II activates sarcolemmal $\mathrm{Na}(+) / \mathrm{H}(+)$ exchanger in adult rat ventricular myocytes. J Cardiovasc Pharmacol 2010, 55:191-197.

55. Liao YF, Hung YC, Chang WH, Tsay GJ, Hour TC, Hung HC, et al: The PKC delta inhibitor, rottlerin, induces apoptosis of haematopoietic cell lines through mitochondrial membrane depolarization and caspases' cascade. Life Sci 2005, 77:707-719.

56. Ringshausen I, Oelsner M, Weick K, Bogner C, Peschel C, Decker T: Mechanisms of apoptosis-induction by rottlerin: therapeutic implications for B-CLL. Leukemia 2006, 20:514-520.

57. Soltoff SP: Rottlerin: an inappropriate and ineffective inhibitor of PKCdelta. Trends Pharmacol Sci 2007, 28:453-458.

58. Blair HC, Teitelbaum SL, Tan HL, Koziol CM, Schlesinger PH: Passive chloride permeability charge coupled to $\mathrm{H}(+)$-ATPase of avian osteoclast ruffled membrane. Am J Physiol 1991, 260:C1315-C1324.

59. Mathur A, Vallano ML: 2,2',3,3',4,4'-Hexahydroxy-1,1'-biphenyl-6,6'dimethanol dimethyl ether (HBDDE)-induced neuronal apoptosis independent of classical protein kinase $C$ alpha or gamma inhibition. Biochem Pharmacol 2000, 60:809-815.

60. Dutil EM, Keranen LM, Paoli-Roach AA, Newton AC: In vivo regulation of protein kinase $C$ by trans-phosphorylation followed by autophosphorylation. J Biol Chem 1994, 269:29359-29362.

61. Newton AC: Protein kinase C: poised to signal. Am J Physiol Endocrinol Metab 2010, 298:E395-E402.

62. Arciuch VG, Alippe $Y$, Carreras MC, Poderoso JJ: Mitochondrial kinases in cell signaling: Facts and perspectives. Adv Drug Deliv Rev 2009, 61:1234-1249.

63. Xu SZ: Rottlerin induces calcium influx and protein degradation in cultured lenses independent of effects on protein kinase $C$ delta. Basic Clin Pharmacol Toxicol 2007, 101:459-464.

\section{Pre-publication history}

The pre-publication history for this paper can be accessed here: http://www.biomedcentral.com/1471-2474/11/250/prepub

\section{doi:10.1186/1471-2474-11-250}

Cite this article as: Sørensen et al:: Screening of protein kinase inhibitors identifies PKC inhibitors as inhibitors of osteoclastic acid secretion and bone resorption. BMC Musculoskeletal Disorders 2010 11:250. 